\title{
Efektivitas Komite Audit Memitigasi Pengaruh Transaksi Pihak Berelasi Terhadap Biaya Audit
}

\author{
Rosdiyati, Fitri Nurjanah dan Indah Kurniawati \\ Universitas Islam Lamongan, Indonesia \\ Email authors: roeshanif@unisla.ac.id/ fitrinurjanah@unisla.ac.id/ \\ indahkurniyawati@unisla.ac.id
}

\begin{abstract}
ABSTRAK
Tujuan penelitian ini untuk membuktikan pengaruh transaksi pihak berelasi terhadap biaya audit dengan moderasi efektivitas komite audit. Metode analisis data yang digunakan adalah statistik deskriptif dan uji hipotesis menggunakan metode Moderated Regression Analysis (MRA) dan dengan menggunakan aplikasi Stata 14. Populasi dalam penelitian ini adalah seluruh perusahaan non keuangan yang terdaftar di Bursa Efek Indonesia selama tahun 20172019. Penelitian ini menggunakan jumlah sampel sebanyak 125 perusahaan.Hasil penelitian menunjukan transaksi pihak berelasi berpengaruh terhadap biaya audit dan efektivitas komite audit tidak memoderasi pengaruh transaksi pihak berelasi terhadap biaya audit.
\end{abstract}

Kata Kunci: Biaya audit, Komite Audit, Transaksi Pihak Berelasi

\section{ABSTRACT}

The purpose of this study is to prove the effect of related party transactions on audit fees by moderating the effectiveness of the audit committee. The data analysis method used was descriptive statistics and hypothesis testing using the Moderated Regression Analysis (MRA) method and using the Stata 14 application. The population in this study were all non-financial companies listed on the Indonesia Stock Exchange during 2017-2019. This study uses a sample of 125 companies. The results show that related party transactions have an effect on audit fees and the effectiveness of the audit committee does not moderate the effect of related party transactions on audit fees.

Keywords: Audit Fees, Audit Committee, Related Party Transactions

\section{PENDAHULUAN}

Transaksi pihak berelasi mencakup aktivitas seperti penjualan dan pembelian aset, dan penjaminan pinjaman.Ada dua pandangan yang bersaing tentang RPT. Sisi positifnya, RPT dapat meningkatkan nilai karena dapat digunakan oleh kelompok bisnis untuk berbagi sumber daya, mengurangi biaya transaksi, dan sebagai hasilnya meningkatkan pengembalian aset. Di sisi lain, RPT sering dianggap melanggar misalnya, RPT dapat digunakan secara oportunistik oleh pemegang saham pengendali yang berurusan sendiri untuk mendapatkan keuntungan pribadi dengan mengorbankan pemegang saham minoritas. Dalam hal ini, pemegang saham pengendali atau perusahaan induk dapat mengatur transaksi melalui pihak terkait untuk mengekstraksi keuntungan pribadi atau mengalihkan sumber daya perusahaan dari pemegang saham minoritas kepada diri mereka sendiri.

Penelitian transaksi pihak berelasi berfokus pada PRT terhadap kualitas laba, masih sangat sedikit penelitian yang meneliti pada respon auditor terhadap RPT (Habib et al. 2015), pada penelitian tersebut meneliti RPT yang memiliki pengaruh terhadap pemilihan auditor. 
Semakin banyak perusahaan terlibat dalam RPT, semakin banyak tantangan yang dihadapi auditor eksternal dan internal. Auditor biasanya melihatnya sebagai "red flag". Levine et al. (1997) berpendapat bahwa karena transparansi yang rendah dan RPT yang rumit dapat mengakhibatkan auditor merasa sulit untuk memahami dan mengaudit transaksi tersebut. Selain itu, American Institute of Certified Public Accountants (AICPA) menganggap RPT sebagai sulit untuk diaudit dan indikator potensial risiko audit (AICPA 2001).

RPT dipandang oleh investor sebagai salah satu alasan utama perusahaan menyajikan kembali laporan keuangan (Gordon dan Henry 2005). Akibatnya, jika auditor yakin bahwa RPT menimbulkan potensi risiko kesalahan penyajian material, mereka cenderung mengenakan biaya yang lebih tinggi untuk mengkompensasi risiko audit dan upaya yang perlu mereka lakukan untuk mengurai transaksi dan memberikan jaminan bahwa RPT tidak bernilai merusak. Sepengetahuan kami, sangat sedikit penelitian yang mengeksplorasi pengaruh RPT terhadap biaya audit (Kohlbeck dan Mayhew 2014; Habib et al. 2015). Salah satu contohnya, oleh Habib et al. (2015), menunjukan pada penlitiannya bahwa biaya audit yang lebih tinggi untuk perusahaan yang terlibat dalam RPT di Tiongkok.

Teorikeagenan membatasi pengambilalihan kekayaan pemegang saham minoritas oleh pemegang saham pengendali. Namun, karena struktur kepemilikan yang terkonsentrasi dan sistem hukum yang lemah, negara-negara Asia Timur menghadapi masalah keagenan yang timbul dari konflik kepentingan dan asimetri informasi antara pemegang saham pengendali dan minoritas (Shleifer dan Vishny 1997; Claessens et al. 2000; La Porta et al. 2000). Oportunistik yang dimiliki pemegang saham pengendali dapat mendorong mereka untuk melakukan RPT untuk keuntungannya sendiri sehingga merugikan pemegang saham minoritas. Lingkungan Malaysia, di mana konsentrasi kepemilikan perusahaan tinggi dan di mana penegakan hukum yang ada untuk melindungi pemegang saham minoritas dan mekanisme tata kelola tidak optimal, merupakan peluang bagus untuk menerapkan teori keagenan.

\section{Pengembangan Hipotesis}

Tata kelola perusahaan adalah serangkaian mekanisme yang mengarahkan dan mengendalikan suatu perusahaan agar perusahaan dapat berjalan sesuai dengan harapan stakeholder (IICG, 2009). Untuk mewujudkan tata kelola perusahaan yang baik, masing-masing pihak dalam suatu perusahaan seperti rapat umum pemegang saham, direksi, dan dewan komisaris memiliki peran yang berbeda-beda, tetapi mereka saling berinteraksi (Ariningrum dan Diyanty, 2017).

Fungsi pengawasan dalam UU Nomor 40 Tahun 2007, Dewan Komisaris dapat membentuk komite di bawahnya yakni Komite Audit, Komite Nominasi dan Komite Remunerasi. Dalam POJK55/POJK.04/2015, setiap perusahaan publik yang terdaftar di Bursa Efek Indonesia harus memiliki Komite Audit. Anggota komite audit wajib mengetahui tentang laporan keuangan perusahaan, bisnis perusahaan yang terkait dengan kegiatan yang dilakukan perusahaan. Perusahaan publik diharuskan memiliki komite audit untuk membantu dewan komisaris terkait fungsi pengawasan mereka. Peran komite audit sangat penting dalam membantu fungsi pengawasan yang dilakukan oleh Dewan Komisaris, terutama berkaitan dengan pengawasan informasi pada laporan keuangan yang dikeluarkan oleh manajemen sebagai salah satu tugas Komite Audit berdasarkan Keputusan Ketua Badan Pengawas Pasar Modal Nomor: Kep-29 / PM / 2004 tanggal 24 September 2004.

Transaksi pihak berelasi banyak menjadi perhatian diantara pelaporan keuangan dan auditing, terutama setelah banyak skandal keuangan yang ada di seluruh dunia.Secara teori transaksi pihak berelasi memiliki dua sudut pandang. Sudut pandang yang pertama transaksi pihak berelasi terkait dengan efficiency-enhancing theory yang menyatakan bahwa transaksi dengan pihak berelasi digunakan oleh kelompok bisinis sebagai cara untuk mengalokasikan sumber daya dengan leih baik dan dapat mengurangi biaya transaksi (Al-Gamrh et al., 2017). 
Selain itu, pihak terkait dengan pengetahuan mendalam dan pengalaman kegiatan perusahaan dapat memberikan layanan kepada perusahaan lebih efektif (Gordon \& Henry, 2005).

Sudut pandnag kedua menyatakan transaksi pihak berelasi dapat menimbulkan isu keagenan, dimana transaksi pihak berelasidapat menyebabkan kerugian atas kegagalan yang dialami perusahaan karena tindakan oportunistik (Kohlbeck \& Mayhew, 2010; Jian \& Wong, 2004). Hubungan pihak berelasi yang signifikan dapat memiliki pengaruh terhadap posisi keuangan dan laba rugi perusahaan.Argumen terkait transaksi pihak berelasi terhadap laporan keuangan, auditor memiliki tanggung jawab untuk mengidentifikasi transaksi pihak berelasi sebagai salah satu resiko salah saji material.Kohlbeck \& Mayhew (2010) menyatakan bahwa transaksi pihak berelasi dapat digunakan sebagai red flag yang dapat meningkatkan resiko sehingga auditor dalam memeriksa laporan keuangan menggunakan upaya yang lebih agar dapat menghasilkan opini yang sesuai.

Simunic (1980) merumuskan bahwa biaya audit dipengaruhi oleh besar kecilnya auditee, komplesitas audit dan resiko yang dimiliki perusahaan. Sehubungan dengan resiko audit, transaksi pihak berelasi merupakan salah satu pertimbangan khusus oleh auditor eksternal dalam melakukan proses audit. Sehingga auditor memerlukan waktu dan upaya untuk melakukan proses audit dan berdampak bada biaya audit (Habib, Jiang, \& Zhou, 2015; AlGamrh, Ismail, \& Ismail, 2017)

H1: transaksi pihak berelasi berpengaruh positif terhadap besaran biaya audit perusahaan.

Tata kelola dalam perusahaan harus dijalankan dengan baik untuk mengurangi masalah agensiyang lebih besar sesuai dengan standart yang diterapkan pada Organisation for Economic Co-operation and Development (OECD). Tata kelola perusahaan berkaitan dengan fungsi pengawasan yang dilakukan oleh dewan komisaris dengan membentuk komite di bawah mereka, salah satunya adalah Komite Audit. Masalah agensi yang besar pada perusahaan yang terkoneksi politik dapat berkurang ketika tata kelola dalam perusahaannya dijalankan dengan baik.

Komite audit yang independen dan memiliki keahlian keuangan dapat meningkatkan kualitas laporan keuangan, pengungkapannya lebih transparan dan lebih efektif dalam melakukan proses audit internal (Owens-Jackson dkk., 2009; Qinghua dkk., 2007; Salehi dan Shirazi, 2016). Ittonen dkk. (2010) menemukan bahwa komposisi komite audit yang berkualitas diyakini dapat meningkatkan tingkat pengawasan dan pengendalian internal, sehingga mengurangi risiko yang dimiliki oleh perusahaan. Risiko yang lebih kecil ini pada akhirnya dapat mengurangi biaya audit karena berkurangnya prosedur pengujian substantif yang perlu dilakukan oleh auditor (Knechel dan Willekens, 2006). oleh karena itu komite audit yang efektif dapat menurunkan pengaruh perusahaan yang memiliki transaksi pihak berelasi terhadap biaya audit.

H2: Efektivitas Komite Audit memoderasi negative pengaruh transaksi pihak berelasi terhadap biaya audit.

\section{MOTODE PENELITIAN}

Populasi penelitian ini merupakan seluruh perusahaan manufaktur yang terdaftar di Bursa Efek Indonesia (BEI) tahun 2017-2018. Penelitian ini menggunakan jenis data sekunder yang diambil dari informasi yang tersaji pada Annual Report.Sebanyak perusahaan terpilih menjadi sampel penelitian berdasarkan teknik purposive sampling dengan kriteria pada 


\begin{tabular}{|c|c|c|c|c|}
\hline No & Kriteria Sampel & 2017 & 2018 & 2019 \\
\hline 1 & Perusahaan manufaktur yang terdaftar di BEI & 143 & 145 & 163 \\
\hline 2 & Laporan keuangan tidak dapat diakses & $(15)$ & (11) & (11) \\
\hline 3 & $\begin{array}{l}\text { Perusahaan yang tidak mengungkapkan biaya } \\
\text { audit }\end{array}$ & (42) & (46) & $(48)$ \\
\hline \multirow[t]{3}{*}{4} & $\begin{array}{l}\text { Perusahaan yang tidak melakukan transaksi } \\
\text { dengan pihak berelasi }\end{array}$ & $(47)$ & $(48)$ & $(58)$ \\
\hline & Total & 39 & 40 & 46 \\
\hline & & \multicolumn{3}{|c|}{125} \\
\hline
\end{tabular}

\section{Definisi operational variabel}

Variabel dependen penelitian adalah biaya audit yang didefiniskan sebagai jumlah biaya yang harus dikeluarkan oleh setiap perusahaan untuk membiayai jasa auditor eksternal yang telah melakukan audit atas laporan keuangan perusahaan yang bersangkutan. Biaya audit diukur dengan logaritma natural biaya audit yang terdapat dalam laporan keuangan.

Variabel independen penelitian adalah transaksi pihak berelasi adalah suatu pengalihan sumber daya, jasa atau kewajiban antara entitas pelapor dengan pihak-pihak yang berelasi, terlepas apakah terdapat harga yang dibebankan atau tidak.Transaksi ini dapat berupa transaksi bisnis yang kompleks antara perusahaan dan manajer, direktur, pemilik utama atau afiliasinya sendiri. Hubungan pihak berelasi dapat dilihat dari substansi hubungan tidak hanya dalam bentuk hukum hubungan tersebut (Wong, Kim, \& Lo, 2015; Cheng \& Leung, 2014; Chen, Chen, \& Chen, 2014).

$$
\begin{gathered}
\mathrm{RPT} \text { _Sales dapat dirumuskan sebagai berikut. } \\
\text { RPT Sales }
\end{gathered}
$$

Variabel moderasi penelitian adalah adalah efektivitas komite audit dan dewan komisaris independen. Efektivitas komite audit yang di definisikan sebagai komite yang memenuhi syarat untuk melindungi kepentingan dari pemegang saham untuk memastikan bahwa pelaporan keuangan andal, pengendalian internal, dan risiko manajemen, melalui upaya melaksanakan pengawasan dengan tekun. Efektivitas komite audit diukur dengan indeks komposit (EFFAC5) dikonfirmasi ketika kelima karakteristik. Lima karakteristik gabungan adalah sebagai berikut: independensi komite audit (IAC), keahlian komite audit (ACEXP), ketekunan komite audit (ACD), ukuran komite audit (SAC) dan ketua komite audit dengan keahlian akuntansi (ACCHX). Sistem skor digunakan dimana nilai dikotomis dari"1" atau "0" untuk setiap karakteristik komite audit yang efektif (Ali dkk., 2018), setelah nilai dari skor efektivitas didapat dirasiokan dengan skor efektivitas komite audit dalam perusahaan dibagi nilai skor sempurna.

Teknik analisis yang digunakan meliputi analisis statistika deskriptif, uji asumsi klasik uji hipotesis (Ghozali, 2011).Analisis statistika deskriptif berisi informasi mengenai karakteristik data penelitian berupa nilai minimum, nilai maksimum, nilai rata-rata dan standar deviasi.Pengujian hipotesis dilakukan menggunakan analisis regresi linear berganda. Berikut model persamaan regresi moderasi dalam penelitian ini:

AudFeeit $=\alpha_{0}+\beta_{1}$ RPT_SALES ${ }_{i t}+\beta_{2}$ LEVit $+\beta_{3}$ SIZEit $+\varepsilon$ it

AudFeeit $=\alpha_{0}+\beta_{4}$ RPT_SALES ${ }_{\text {it }}+\beta_{5}$ EFFACit $+\beta_{6}$ LEVit $+\beta_{7}$ SIZEit + cit (2)

AudFeeit $=\alpha_{0}+\beta_{8}$ RPT_SALES ${ }_{i t}+\beta_{9}$ RPT_SALES $*$ EFFAC $_{i t}+\beta_{10}$ EFFACit $+\beta_{11}$ LEVit + $\beta_{12}$ SIZEit $+\operatorname{cit}(3)$

Keterangan:

AudFee

$\alpha_{0}$

$=$ Audit Fee yang dikeluarkan oleh entitas go-publik

$=$ Konstanta 


$\begin{array}{ll}\text { RPT_SALES } & =\text { Transaksi pihak berelasi perusahaan } i \text { tahun } t \\ \text { EFFAC } & =\text { Effektivitas komite audit } \\ \text { SIZE } & =\text { Ukuran perusahaan } \\ \text { LEV } & =\text { Leverage }\end{array}$

\section{HASIL PEMBAHASAN}

\section{Hasil Statistik Deskriptif}

Berdasarkan tabel statistik deskriptif di bawah ini, dapat diketahui bahwa variabel dependen dalam penelitian ini yaitu biaya audit memiliki nilai rata-rata sebesar 21.00284 dalam rupiah berarti Rp 940 juta, ini berarti bahwa rata-rata perusahaan di Indonesia pada 2017 sampai 2019 membayar jumlah biaya audit sebesar Rp 940 juta kepada auditor. Rentang ini cukup tinggi pada variabel ini, dilihat dari perbedaan antara nilai maksimum dan minimum, menggambarkan bahwa sampel perusahaan dalam penelitian ini mewakili jumlah nominal biaya audit dari kecil ke besar.

Tabel 2. Statistik Deskriptif

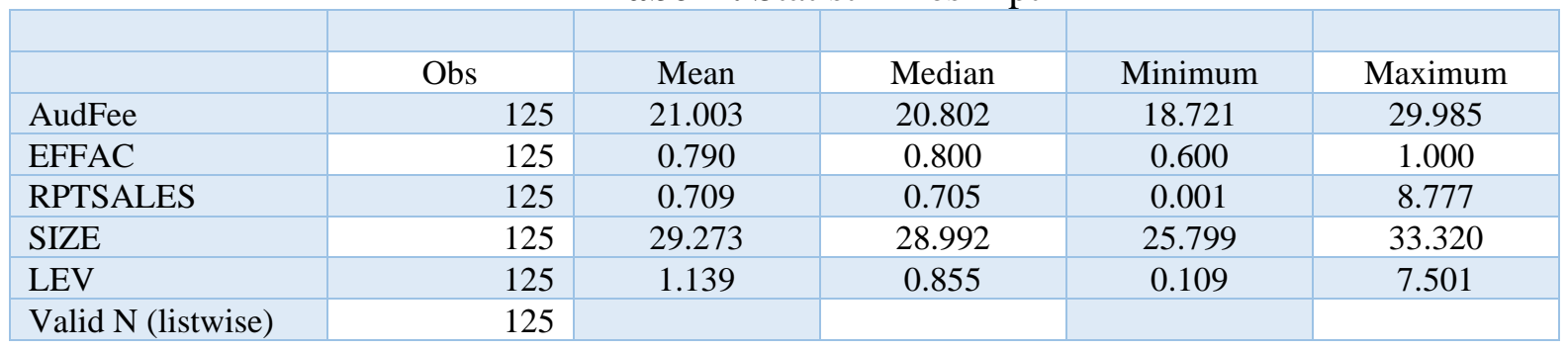

Tabel 3. Person Correlation

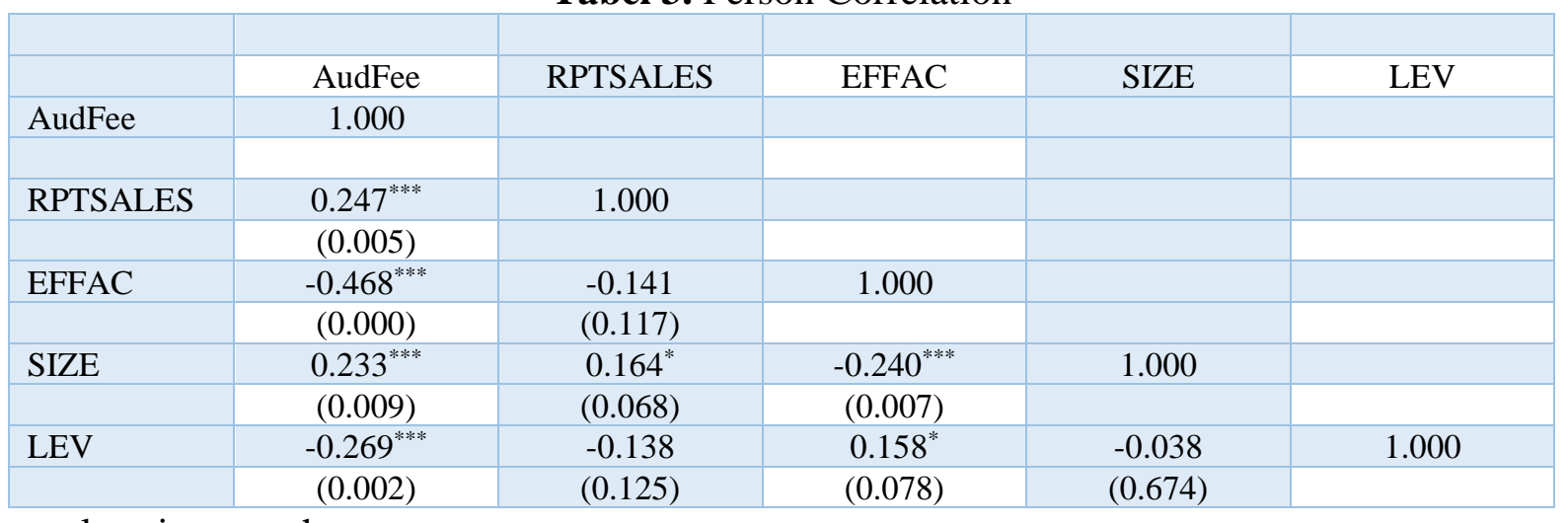

$p$-values in parentheses

${ }^{*} p<0.1,{ }^{* *} p<0.05,{ }^{* * *} p<0.01$ 
Tabel 4.Regresi linier Berganda

\begin{tabular}{|l|c|c|c|}
\hline & $(1)$ & $(2)$ & $(3)$ \\
\hline & AudFee & AudFee & AudFee \\
\hline RPTSALES & $0.341^{* *}$ & $0.278^{*}$ & 2.443 \\
\hline SIZE & $(2.14)$ & $(1.89)$ & $(1.58)$ \\
\hline & $0.203^{* *}$ & 0.112 & 0.119 \\
\hline LEV & $(2.28)$ & $(1.34)$ & $(1.42)$ \\
\hline & $-0.357^{* *}$ & $-0.275^{* *}$ & $-0.298^{* *}$ \\
\hline EFFAC & $(-2.80)$ & $(-2.33)$ & $(-2.52)$ \\
\hline EFFAC*RPT_Sales & & $-4.689^{* *}$ & $-2.933^{*}$ \\
\hline & & $(-4.89)$ & $(-1.87)$ \\
\hline _cons & & & -2.691 \\
\hline & & & $(-1.41)$ \\
\hline r2 & $15.215^{* *}$ & $21.542^{* *}$ & $19.913^{* *}$ \\
\hline$N$ & $(5.85)$ & $(7.94)$ & $(6.78)$ \\
\hline
\end{tabular}

$t$ statistics in parentheses

${ }^{*} p<0.1,{ }^{* *} p<0.05,{ }^{* *} p<0.01$

\section{Robust test}

Tabel 5. Uji Robust

\begin{tabular}{|l|c|c|c|}
\hline & $(1)$ & $(2)$ & $(3)$ \\
\hline & AudFee & AudFee & AudFee \\
\hline RPT_Sales & 0.341 & 0.278 & 2.443 \\
\hline SIZE & $(1.38)$ & $(1.39)$ & $(1.52)$ \\
\hline & 0.203 & 0.112 & 0.119 \\
\hline LEV & $(1.16)$ & $(0.62)$ & $(0.67)$ \\
\hline & $-0.357^{* * *}$ & $-0.275^{* * *}$ & $-0.298^{* * *}$ \\
\hline EFFAC & $(-3.54)$ & $(-4.09)$ & $(-4.13)$ \\
\hline & & $-4.689^{* * * *}$ & $-2.933^{*}$ \\
\hline EFFAC*RPT_Sales & & $(-3.14)$ & $(-1.94)$ \\
\hline & & & -2.691 \\
\hline & & & $(-1.40)$ \\
\hline & & & $19.913^{* * * *}$ \\
\hline r2 & $15.215^{* * *}$ & $21.542^{* * * *}$ & $(3.27)$ \\
\hline$N$ & $(2.90)$ & $(3.34)$ & 0.306 \\
\hline
\end{tabular}

$t$ statistics in parentheses

${ }^{*} p<0.1,{ }^{* *} p<0.05,{ }^{* * *} p<0.01$

Tabel 5 merupakan hasil uji robust.Dalam pengujian regresi ditemukan hal-hal yang dilanggar dalam pengujian asumsi klasik. Pengujian ini dapat dilakukan untuk mengurangi bias dari hasil penelitian dan penting untuk menganalisis data yang dipengaruhi oleh outlier dan meminimalkan pengaruh outlier terhadap suatu model sehingga akan diperoleh model yang terbaik. Temuan ini juga kuat dengan hampir tidak ada perbedaan dengan ordinary least square dengan tingkat signifikan.

\section{Pengaruh transaksi pihak berelasi terhadap Biaya Audit}

Hasil penelitian yang dilakukan pada model penelitian ini menunjukan bahwa hasilnya konsisten dengan hipotesis kedua yang menyatakan bahwa transaksi pihak berelasi berpengaruh positif signifikan terhadap biaya audit. Penjelaskan hasil penelitian ini menunjukan transaksi pihak berelasi pada laporan keuangan berelasi dapat digunakan sebagai 
red flag yang dapat meningkatkan resiko sehingga auditor dalam memeriksa laporan keuangan menggunakan upaya yang lebih agar dapat menghasilkan opini yang sesuai. Sudut pandnag kedua menyatakan transaksi pihak berelasi dapat menimbulkan isu keagenan, dimana transaksi pihak berelasi dapat menyebabkan kerugian atas kegagalan yang dialami perusahaan karena tindakan oportunistik (Kohlbeck \& Mayhew, 2010; Jian \& Wong, 2004). Hubungan pihak berelasi yang signifikan dapat memiliki pengaruh terhadap posisi keuangan dan laba rugi perusahaan.Argumen terkait transaksi pihak berelasi terhadap laporan keuangan, auditor memiliki tanggung jawab untuk mengidentifikasi transaksi pihak berelasi sebagai salah satu resiko salah saji material.Kohlbeck \& Mayhew (2010) menyatakan bahwa transaksi pihak berelasi dapat digunakan sebagai red flag yang dapat meningkatkan resiko sehingga auditor dalam memeriksa laporan keuangan menggunakan upaya yang lebih agar dapat menghasilkan opini yang sesuai.

Simunic (1980) merumuskan bahwa biaya audit dipengaruhi oleh besar kecilnya auditee, komplesitas audit dan resiko yang dimiliki perusahaan. Sehubungan dengan resiko audit, transaksi pihak berelasi merupakan salah satu pertimbangan khusus oleh auditor eksternal dalam melakukan proses audit. Sehingga auditor memerlukan waktu dan upaya untuk melakukan proses audit dan berdampak bada biaya audit (Habib, Jiang, \& Zhou, 2015; AlGamrh, Ismail, \& Ismail, 2017).

\section{Pengaruh transaksi pihak berelasi terhadap biaya audit dimoderasi efektivitas Komite Audit.}

Hasil penelitian yang dilakukan pada model penelitian ini menunjukan bahwa hasilnya menunjukan bahwa efektivitas komite audit tidak memoderasi pengaruh transaksi pihak berelasi terhadap biaya audit. Komite audit dalam tata kelola perusahaan dibawahi oleh komisaris independen dalam mengawasi manajemen perusahaan. Komite audit memiliki tugas dan tanggung jawab antara lain melakukan penelaahan atas informasi keuangan yang akan dikeluarkan Perusahaan kepada publik dan/atau pihak otoritas antara lain laporan keuangan, proyeksi, dan laporan lainnya terkait dengan informasi keuangan Perusahaan. Komite audit tidak memoderasi pengaruh transaksi pihak berleasi terhdap biaya audit dikarenakan komite audit tidak memiliki kewenangan untuk membatasi transaksi dengan pihak berelasi yang dilakukan oleh perusahaan.

\section{KESIMPULAN}

Penelitian ini bertujuan untuk mengetahui hasil empiris pengaruh transaksi pihak berelasi terhadap biaya audit dan efektivitas komite audit memitigasi pengaruh transaksi pihak berlasi terhadap biaya audit. Pengujian pertama menguji transaksi pihak berelasi berpengaruh terhadap biaya audit.Berdasarkan hasil pengujian hipotesis pertama ditemukan bahwa transaksi pihak berelasi berpengaruh positif terhadap biaya audit. Perusahaan yang mempunyai transaksi pihak berelasi dapat menyebabkan kerugian atas kegagalan yang dialami perusahaan karena tindakan oportunistik (Kohlbeck \& Mayhew, 2010; Jian \& Wong, 2004) hal tersebut dapat meningkatkan upaya audit dalam melakukan audit sehingga biaya audit yang dikeluarkan akan tinggi. Hipotesis kedua menunjukan bahwa efektivitas komite audit tidak memoderasi pengaruh transaksi pihak berelasi terhadap biaya audit. Penelitian ini memiliki keterbatasan, yang pertama masih sedikitnya perusahaan yang mengungkapkan biaya audit dalam laporan tahunannya, saran untuk penelitian selanjutnya menggunakan variabel tata kelola untuk dijadikan variabel moderasi. 


\section{DAFTAR PUSTAKA}

Al-Gamrh, R. A. A. B., Ismail, K. N. I. K., \& Ismail, S. S. H. (2017). Related party transactions and audit fees: the role of the internal audit function. Journal of Management \& Governance. https://doi.org/10.1007/s10997-017-9376-6

Ali, M. J., Singh, R. K. S., \& Al-Akra, M. (2018). The impact of audit committee effectiveness on audit fees and non-audit service fees: Evidence from Australia. Accounting Research Journal, 31(2), 174-191.

Ariningrum, I., \& Diyanty, V. (2017). The Impact of Political Connections and the Effectiveness of Board of Commissioner and Audit Committees on Audit Fees The Impact of Political Connections and the Effectiveness of Board of. 11(4), 53-70. https://doi.org/10.14453/aabfj.v11i4.5

Atanasov, V., Black, B., \& Ciccotello, C. S. (2014). UNBUNDLING AND MEASURING TUNNELING *. 1697-1738.

Chen, Y., Chen, C. H., \& Chen, W. (2014). The Impact of Related Party Transactions on The Operational Performance of Listed Companies in China. Journal of Economic Policy Reform, 12 (December),

285-297. https://doi.org/https://doi.org/10.1080/17487870903314575

Cheng, M., \& Leung, N. W. (2014). Ownership Structure, Ongoing Related Party Transaction and Corporate Performance: Evidenced from Chinese Listed Firms. Corporate Ownership \& Control, 11(2), 446-464. https://doi.org/10.22495/cocv11i2c5p2

Ghozali, I. (2013). Analisis Multivariate dengan Program IBM SPSS 21: Semarang: Universitas Diponegoro.

Erasandi, S. (2020). Related Party Transaction Berpengaruh Terhadap Biaya Audit. Journal of Accounting Science, 4(1), 1-11. https://doi.org/10.21070/jas.v4i1.393

Fisip, H. (2020, June). PROSIDING SLAMET RIYADI CONFERENCE ON PUBLIC ADMINISTRATION (SRIPA). In PROSIDING: SLAMET RIYADI CONFERENCE ON PUBLIC ADMINISTRATION (SRIPA) (Vol. 2, No. 1).

Gordon, E. A., \& Henry, E. (2005). Related Party Transactions and Earnings Management.

Habib, A., Jiang, H., \& Zhou, D. (2015). Related-Party Transactions and Audit Fees: Evidence from China. Journal of International Accounting Research, 14(1), 59-83.

Jensen, M. C., \& Meckling, W. H. (1976). Theory of the firm: Managerial behavior, agency costs and ownership structure. Journal of Financial Economics, 3(4), 305-360. https://doi.org/10.1016/0304-405X(76)90026-X

Jian, M., \& Wong, T. J. (2004). Earnings Management and Tunneling through Related Party Transactions : Evidence from Chinese Corporate Groups .

Knechel, W. R., \& Willekens, M. (2006). The role of risk management and governance in determining audit demand. Journal of Business Finance \& Accounting, 33(9-10), 13441367.

Kohlbeck, M., \& Mayhew, B. W. (2010). Valuation of firms that disclose related party transactions. Journal of Accounting and Public Policy, 29(2), 115-137.

Nurjanah, F., \& Sudaryati, E. (2019). The effect of political connection and effectiveness of audit committee on audit fee. The Indonesian Accounting Review, 9(2), 227. https://doi.org/10.14414/tiar.v9i2.1848

Owens-Jackson, L. A., Robinson, D., \& Waller Shelton, S. (2009). The association between audit committee characteristics, the contracting process and fraudulent financial reporting. American Journal of Business, 24(1), 57-66.

Salehi, M., \& Shirazi, M. (2016). Audit committee impact on the quality of financial reporting and disclosure: Evidence from the Tehran Stock Exchange. Management Research Review, 39(12), 1639-1662. 
Simunic, D. A. (1980). The Pricing of Audit Service: Theory and Evidence. Jurnal of Accounting Research, 18(1), 161-190.

Susanti, I., Syairozi, M. I., \& Lukman, H. Y. W. (2021). Analisis Sistem Manajemen Dalam Pengelolaan Bumdes Di Desa Bluluk. Jurnal Sains Sosio Humaniora, 5(2), 701-710.

Syairozi, M. I. (2017). Percepatan Pengurangan Kemiskinan Sektor Pertanian di Kabupaten Malang. In Seminar Nasional \& Call For Paper, FEB Unikama (pp. 145-155).

Tuanakotta, T. M. (2015). Audit Kontemporer. Jakarta: salemba empat.

Qinghua, W., Pingxin, W., \& Junming, Y. (2007). Audit committee, board characteristics and quality of fi nancial reporting: An empirical research on Chinese securities market. Frontiers of Business Research in China, 1(3), 385-400.

Wahab, E. A. A., Zain, M. M., \& James, J. (2011). Political connections, corporate governance and audit fees in Malaysia. Managerial Auditing Journal, 26(5), 393-418.

Wong, R. M. K., Kim, J., \& Lo, A. W. Y. (2015). Are Related-Party Sales Value-Adding or Value-Destroying? Evidence from China. Journal of International Finance Manangement \& Accounting, 26(1), 1-38. https://doi.org/https://doi.org/10.1111/jifm.12023 